Bangladesh J. Plant Taxon. 20(2): 163-170, 2013 (December)

(C) 2013 Bangladesh Association of Plant Taxonomists

\title{
REPRODUCTIVE BIOLOGY OF SEVEN TAXA OF MAGNOLIA L. IN THE SOUTH OF RUSSIAN FAR EAST
}

\author{
Lyubov A. Kameneva And InNA M. KoKSheeva ${ }^{1}$ \\ Botanical Garden-Institute, Far Eastern Branch of Russian Academy of Sciences (BGI FEB RAS), \\ Vladivostok, Russia.
}

Keywords: Magnolia L.; Pollen; Seed germination; Stratification; Seed productivity.

\begin{abstract}
This paper presents the phenology of seven taxa of the genus Magnolia L., pollen biology on germination and storage conditions, seed productivity, germinating ability of seeds and its dependence on stratification and germination conditions. It has been found that M. kobus DC, M. kobus var. boreales Sarg., M. obovata Thurb., M. officinalis Rehd. et Wils., M. salicifolia (Sieb. et Zucc.) Maxim., M. sieboldii K. Koch. and M. tripetala L. in cultivated condition produce pollen at a low viability rate $(9.4-31.7 \%)$. Real seed productivity of the taxa being studied is less than their potential productivity. However, M. obovata, $M$. officinalis and $M$. tripetala are characterized by high seed germinating ability, up to $94 \%$. Optimal germination conditions for seeds of M. tripetala, $M$. officinalis and $M$. obovata require protected ground (greenhouse) and stratification at $4^{\circ} \mathrm{C}$ during 30 days. The high germinating ability of $M$. sieboldii seeds in the open ground is explained by stratification duration and temperature required for this species. Sarcotesta effects on higher seed germinating ability have been observed in M. obovata only.
\end{abstract}

\section{Introduction}

Magnolia, belonging to the family Magnoliaceae Juss. includes over 80 species, and is distributed in Southeast Asia, North and Central America (Low, 1996). The only Magnolia species that occurs in Russia is Magnolia obovata Thunb., growing in Kunashir Islands (Barkalov, 2009). Primorsky Krai has favourable climatic conditions for the cultivation of representatives of the genus Magnolia (Turkenya, 1991). This fact has made it possible to bring some other magnolia species under cultivation in this area.

The collection of Magnolia in the Botanical Garden-Institute, Far Eastern Branch of Russian Academy of Sciences (BGI FEB RAS), Vladivostok (Russia, Far East, Primorsky Krai), dates back to 1972 and at that time some seeds of $M$. sieboldii K. Koch. were brought from the Pyongyang Botanical Garden (North Korea). Forty years later, there are 20 magnolia species successfully cultivated in the Botanical Garden Institute FEB RAS.

Prospects for bringing plants under cultivation are assessed by correspondence of plant phenology with climatic conditions in which they grow. Knowledge of pollen quality, pollination and fertilization issues and production of quality seed material has both theoretical and practical importance. Pollen quality is important for prediction of seed productivity of plants and for hybridization studies (Termena, 1972; Koksheeva, 2004; Pshennikova, 2007; Liza et al., 2010). Production of quality seed material is an indicator of reproductive capacity of plants which depends on a number of factors: morphogenetic, genetic, physiological and ecological.

\footnotetext{
${ }^{1}$ Corresponding author. Email: koksheeva@yandex.ru
} 
Individual questions of reproductive biology of some species of magnolia in different climatic conditions have been studied by several authors (Minchenko and Korshuk, 1987; Kikuzawa and Mizui, 1990; Ishida, 1996; Grigorenko, 1998; Hirayama and Ishida, 2005; Korshuk and Palagecha, 2007; Setsuko et al., 2008; Han and Long, 2010; Wang, 2010). The present work deals with comprehensive study of the genus Magnolia in the Russian Far East, including the study of phenology, pollen germination, seed productivity and seed germination.

\section{Materials and Methods}

Seven taxa of Magnolia growing in the Botanical Garden Institute in Vladivostok (Russian Far East, Primorsky Krai) are appended in Table 1. Observations on phenology have been made using the methodology of Lapin (1967).

Table 1. List of taxa of Magnolia L. used in the present study.

\begin{tabular}{|c|c|c|c|c|c|}
\hline \multirow[b]{2}{*}{ Taxa } & \multirow[b]{2}{*}{ Locality } & \multirow[b]{2}{*}{ Origin material } & \multirow[b]{2}{*}{$\mathrm{h} / \mathrm{d}(\mathrm{m})$} & \multicolumn{2}{|c|}{ Beginning } \\
\hline & & & & $\begin{array}{c}\text { flowering } \\
\text { (year) }\end{array}$ & $\begin{array}{c}\text { fruiting } \\
\text { (year) }\end{array}$ \\
\hline M. kobus & $\begin{array}{l}\text { Central and } \\
\text { northern Japan, } \\
\text { southern part of } \\
\text { the Korean } \\
\text { Peninsula }\end{array}$ & $\begin{array}{l}\text { Ukraine, Kiev, Institute of } \\
\text { Botanical Gardens, 1984, } \\
\text { seedlings }\end{array}$ & $4.5 / 5.0$ & 9 & 9 \\
\hline $\begin{array}{l}\text { M. kobus var. } \\
\text { borealis }\end{array}$ & Japan, Hokkaido & $\begin{array}{l}\text { Ukraine, Kiev, Institute of } \\
\text { Botanical Gardens, 1984, } \\
\text { seedlings }\end{array}$ & $05.0 / 5.0$ & 14 & 26 \\
\hline M. obovata & $\begin{array}{l}\text { Japan, Kuril } \\
\text { Islands, Russia }\end{array}$ & $\begin{array}{l}\text { Ukraine, Kiev, Institute of } \\
\text { Botanical Gardens, 1986, } \\
\text { seedlings }\end{array}$ & $3.0 / 3.0$ & 13 & 24 \\
\hline M. officinalis & Central China & $\begin{array}{l}\text { Ukraine, Kiev, Institute of } \\
\text { Botanical Gardens, 1989, } \\
\text { seedlings }\end{array}$ & $4.5 / 5.0$ & 16 & 20 \\
\hline M. salicifolia & $\begin{array}{l}\text { Central and } \\
\text { northern Japan }\end{array}$ & Czech Republic, 1996, seeds & $63.5 / 3.5$ & 13 & 15 \\
\hline M. sieboldii & $\begin{array}{l}\text { Japan, China, the } \\
\text { Korean Peninsula }\end{array}$ & $\begin{array}{l}\text { North Korea, Pyongyang, the } \\
\text { Botanical Gardens, 1974, seeds }\end{array}$ & $04.0 / 6.0$ & 9 & 14 \\
\hline M. tripetala & $\begin{array}{l}\text { The southern part } \\
\text { of North America }\end{array}$ & $\begin{array}{l}\text { Ukraine, Kiev, Institute of } \\
\text { Botanical Gardens, 1988, } \\
\text { seedlings }\end{array}$ & $4.0 / 2.0$ & 12 & 22 \\
\hline
\end{tabular}

$\mathrm{h}=$ height of stem, $\mathrm{d}=$ diameter of crown of tree.

Pollen was collected during mass flowering period. Three growth medium varieties were used for study of pollen germination: $5 \%, 10 \%$ and $15 \%$ glucose solutions, with distilled water used for control purposes (Golubinsky, 1974). Pollen was germinated in a thermostat at $24^{\circ} \mathrm{C}$ and laboratory temperature $18^{\circ} \mathrm{C}$ to $20^{\circ} \mathrm{C}$. Specimens were observed through a microscope through $24 \mathrm{~h}$ after pollen was sown. The number of germinated pollen grains was counted in five microscope fields of view for each specimen. The length of pollen tubes was measured as an indicator of pollen viability. An optimal growth medium was assumed in which germinated pollen percentage was at its highest and corresponded to maximum length of pollen tubes. 
Three storage methods were used to determine optimal conditions of pollen storage: storage in laboratory conditions at $18^{\circ} \mathrm{C}$ to $20^{\circ} \mathrm{C}$, storage in a household refrigerator at $4^{\circ} \mathrm{C}$ and storage in a freezing cabinet at $-18^{\circ} \mathrm{C}$. Pollen was stored for 7 days in tight sealed test tubes.

Seed productivity and productivity rate were determined using the method of Rabotnov (1960). Potential seed productivity (PSP) is number of seed buds per one fruit aggregate. Real seed productivity (RSP) is number of mature seeds per one fruit aggregate. Productivity rate (PR) is the ratio of potential and real seed productivity expressed in per cent. Seed productivity studies were based on 60 fruit aggregates taken for each plant. Seed and fruit parameters were also measured: length, width and weight (weight of 1,000 seeds with/without sarcotesta). Seed germinating ability was determined by sowing seeds in the open ground and in the protected ground (greenhouse) and further natural lengthy (mean air temperature in winter varying from $-5^{\circ} \mathrm{C}$ to $-27.2^{\circ} \mathrm{C}$ ) stratification and artificial stratification (at $4^{\circ} \mathrm{C}$ during 30 days). Also, seeds were germinated with and without sarcotesta. Studies were based on 90 seeds of each species taken for each experimental condition.

\section{Results and Discussion}

\section{Phenology of plants:}

Vegetative period of Magnolia species begins with swelling of generative buds (20 April 2012) at temperature around $5.4^{\circ} \mathrm{C}$. Vegetative buds swell later (5-28 May 2012). For all the seven Magnolia taxa studied, flowering period normally begins 10-20 days after commencement of generative bud swelling and continues for 17 to 40 days (Fig. 1A-C). The flowering of early flowering Magnolia species occurs before leaf unfolding period and mass flowering occurs in mid-May at $9.7^{\circ} \mathrm{C}$. Mass flowering of late flowering Magnolia species, which flower after leaf unfolding, occurs in mid-June at $14.5^{\circ} \mathrm{C}$. In the south of Primorsky Krai, seeds ripen in late September or in first ten-day period of October $\left(16.5^{\circ} \mathrm{C}\right)$. Vegetation period duration for the species being studied is 169-179 days (Table 2).

Table 2. Phenology of the genus Magnolia L. in cultivated condition.

\begin{tabular}{|c|c|c|c|c|c|c|c|c|c|c|c|}
\hline \multirow{3}{*}{ Taxa } & \multirow{2}{*}{$\begin{array}{l}\text { Genera- } \\
\text { tive bud } \\
\text { swelling }\end{array}$} & \multirow{2}{*}{$\begin{array}{l}\text { Vegeta- } \\
\text { tive buds } \\
\text { swelling }\end{array}$} & \multirow{2}{*}{$\begin{array}{l}\text { Leaf } \\
\text { unfold- } \\
\text { ing }\end{array}$} & \multirow{2}{*}{$\begin{array}{l}\text { Bud- } \\
\text { ding }\end{array}$} & \multicolumn{3}{|c|}{ Flowering } & \multirow{2}{*}{$\begin{array}{l}\text { Fruit } \\
\text { forma- } \\
\text { tion }\end{array}$} & \multirow{2}{*}{$\begin{array}{l}\text { Fruit } \\
\text { ripen- } \\
\text { ing }\end{array}$} & \multirow{2}{*}{$\begin{array}{l}\text { Defo- } \\
\text { liation }\end{array}$} & \multirow{2}{*}{$\begin{array}{l}\text { Vegeta- } \\
\text { tion period } \\
\text { (days) }\end{array}$} \\
\hline & & & & & Start & Mass & Stop & & & & \\
\hline & \multicolumn{11}{|c|}{ Date } \\
\hline M. kobus & 20.04 & 16.05 & 27.05 & 29.04 & 05.05 & 15.05 & 22.05 & 02.10 & 16.10 & 03.11 & 179 \\
\hline $\begin{array}{l}\text { M. kobus } \\
\text { var. borealis }\end{array}$ & 23.04 & 16.05 & 27.05 & 30.04 & 03.05 & 18.05 & 25.05 & 01.10 & 18.10 & 28.10 & 173 \\
\hline M. obovata & 9.05 & 22.05 & 28.05 & 5.06 & 16.06 & 18.06 & 9.07 & 3.10 & 12.10 & 26.10 & 172 \\
\hline M. officinalis & 10.05 & 28.05 & 29.05 & 6.06 & 14.06 & 17.06 & 9.07 & 8.10 & 13.10 & 26.10 & 169 \\
\hline M. salicifolia & 21.04 & 05.05 & 10.05 & 28.04 & 03.05 & 19.05 & 03.06 & 02.10 & 13.10 & 25.10 & 175 \\
\hline M. sieboldii & 29.04 & 08.05 & 20.05 & 24.05 & 6.06 & 20.06 & 18.07 & 27.09 & 08.10 & 25.10 & 169 \\
\hline M. tripetala & 7.05 & 19.05 & 5.05 & 13.06 & 19.06 & 20.06 & 12.07 & 27.09 & 9.10 & 27.10 & 175 \\
\hline
\end{tabular}

\section{Pollen germination biology:}

Seed productivity of plants is known to be largely dependent on pollen viability. Pollen quality is governed by many factors, viz. species particulars, climatic conditions for growing and pollen maturity. Pollen germination results for seven taxa of Magnolia genus on various growth mediums are shown in Table 3. Pollen germination in laboratory conditions at temperature 
$18-20^{\circ} \mathrm{C}$ revealed that its viability does not exceed $4.8 \%$. Because of that, further pollen germination studies were continued in a thermostat at $24^{\circ} \mathrm{C}$. This temperature increase resulted in a higher percentage of pollen viability and longer pollen tubes (Fig. 1L).
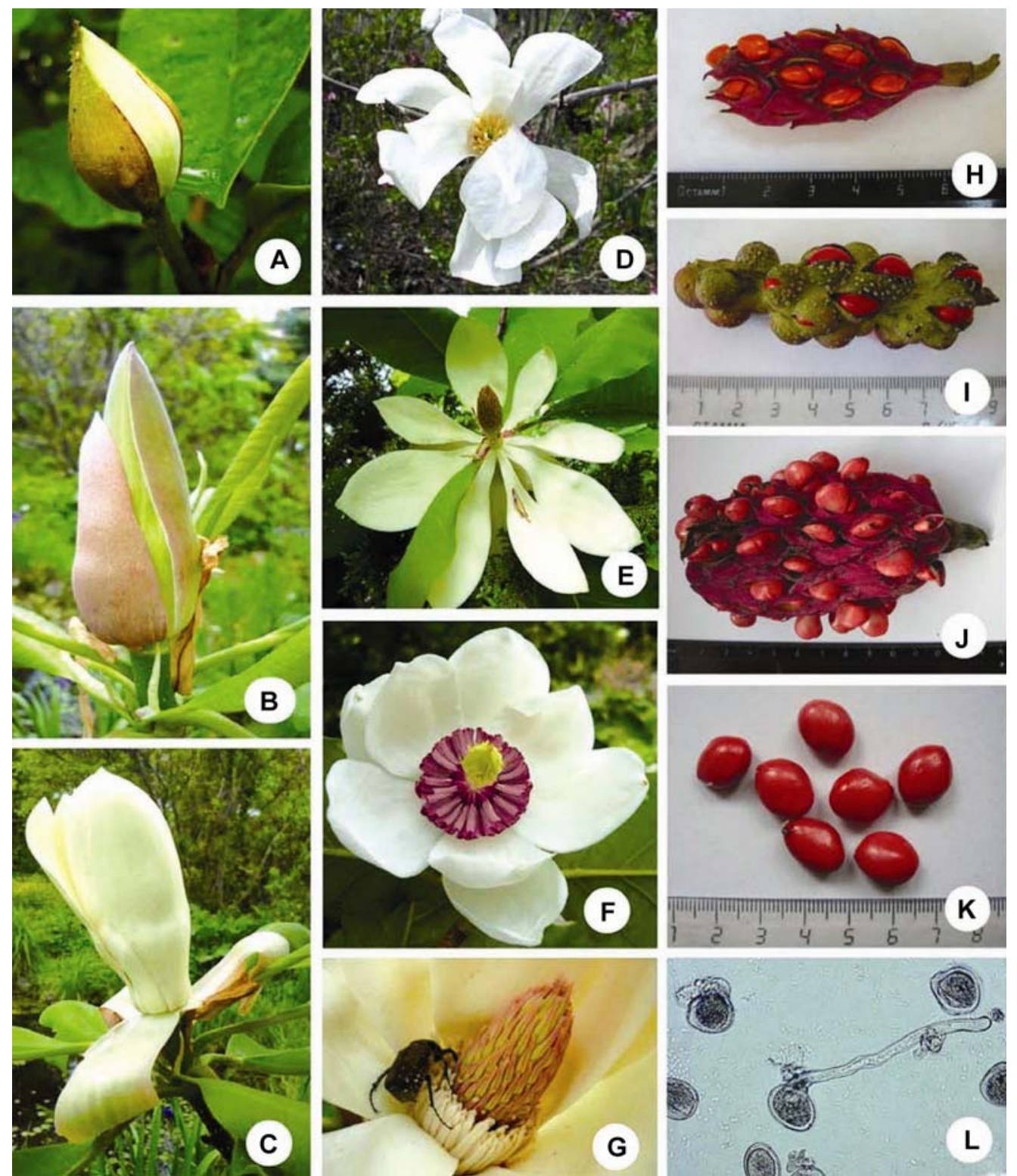

Fig. 1. Development stages of the genus Mognolia: Magnolia sieboldii (A. budding; F. flower; H. fruit); Magnolia officinalis (B,C. budding; E,G. flowers; K. seeds); Magnolia kobus (D. flower); Magnolia kobus var. borealis (I. fruit; L. pollen); Magnolia obovata (J. fruit).

Pollen germination results for Magnolia taxa in a thermostat at $24^{\circ} \mathrm{C}$ on various growth mediums showed that the optimal medium is a $5 \%$ glucose solution in which the percentage of 
germinated pollen was at its highest and corresponded to the maximum length of pollen tubes. In general, the taxa being studied are characterized by low pollen viability from $9.4 \%$ to $31.7 \%$. Among these species, highest viability data were registered for pollen of M. kobus var. borealis $(31.7 \%)$ with a pollen tube length of $8.2 \mu \mathrm{m}$. Low pollen viability data were observed for M. kobus $(9.4 \%)$, with its flowering period occurring in early May $\left(9.7^{\circ} \mathrm{C}\right)$. These data are supported by Minchenko and Korshuk (1987) showing that the main reason for poor pollen viability (in a cultivated condition in Kiev, Ukraine) may be low temperatures during flowering period preventing complete maturation of pollen.

Table 3. Magnolia pollen viability in different growth medium.

\begin{tabular}{lccc}
\hline \multirow{2}{*}{ Taxa } & \multicolumn{3}{c}{ Glucose concentration (\%) } \\
\cline { 2 - 4 } M. kobus & $\frac{9.4 \pm 1.2}{46+2.9}$ & $\frac{6.1 \pm 0.8}{5.5 \pm 1.9}$ & $\frac{3.5 \pm 0.6}{5.8 \pm 1.9}$ \\
M. kobus var. borealis & $\frac{31.7 \pm 2.8}{34.3 \pm 2.6}$ & $\frac{10.2 \pm 2.6}{5.8 \pm 1.8}$ & $\frac{5.2 \pm 0.6}{4.7 \pm 1}$ \\
M. obovata & $\frac{11.3 \pm 1.4}{-}$ & $\frac{6.1 \pm 0.9}{-}$ & $\frac{3.4 \pm 0.6}{-}$ \\
M. officinalis & $\frac{13.8 \pm 1.7}{-}$ & $\underline{11.7 \pm 1.3}$ & $\underline{-}$ \\
M. salicifolia & $\frac{10.4 \pm 1.2}{62+1.2}$ & $\frac{7.06 \pm 1.09}{5.3 \pm 1.3}$ & $\frac{1.3 \pm 0.4}{5.02+1.1}$ \\
M. sieboldii & $\frac{19.6 \pm 1.4}{8.2 \pm 1.5}$ & $\frac{14.2 \pm 1.1}{3.9 \pm 0.09}$ & $\frac{5.6 \pm 0.8}{2.2 \pm 0.3}$ \\
M. tripetalla & - & - & - \\
\hline
\end{tabular}

In the numerator - pollen viability (\%), denominator - the length of pollen tubes $(\mu \mathrm{m})$; «-» not examined.

Pollen ability to be stored during a long time is an important feature for hybridization studies. Results of pollen storage of Magnolia for different temperature conditions showed that pollen of all taxa being studied rapidly loses its viability at $18-20^{\circ} \mathrm{C}$ (Fig. 2). Highest pollen viability data were observed for $M$. officinalis $(8 \%)$ when stored in a freezing cabinet at $-18^{\circ} \mathrm{C}$. However, this temperature of $-18^{\circ} \mathrm{C}$ adversely affected pollen viability during storage for the rest taxa being studied. Therefore, an optimal pollen storage condition for the majority of species is a lowered above-zero temperature of $4^{\circ} \mathrm{C}$. Pollen storage results for Magnolia species are confirmed by data of Minchenko and Korshuk (1987) who indicated that even five-day-long storage of magnolia pollen reduces its viability twice and more and that such pollen cannot be used for hybridization.

\section{Seed productivity:}

Results of seed productivity studies for seven taxa of Magnolia in a cultivated condition in the south of the Russian Far East are presented in Table 4. Potential seed productivity of the species being studied is defined by the number of seed buds per one fruit aggregate, being an upper limit of a species' seed productivity, and characterizes its potential that is little dependent on environmental conditions. Potential seed productivity varies depending on species and is equal to 48-210 ovules per one fruit aggregate. Real seed productivity was found by the number of seeds beginning to develop in a fruit. It amounted up to 55 seeds per one fruit aggregate which is much lower than potential seed productivity. Despite low real seed productivity, productivity rate for $M$. sieboldii and $M$. tripetala is above $50 \%$. The lowest productivity rate was registered for $M$. salicifolia $(1.7 \%)$. 
Table 4. Seed productivity of seven taxa of Magnolia in cultivated condition.

\begin{tabular}{lccc|ccccccc}
\hline \multirow{2}{*}{ Taxa } & \multicolumn{4}{c}{ PSP } & \multicolumn{3}{c}{ RSP } & \multicolumn{3}{c}{ PR (\%) } \\
\cline { 2 - 10 } & Min & Max & Mean & Min & Max & Mean & Min & Max & Mean \\
\hline M. kobus & 26 & 66 & 74 & 9 & 31 & 11 & 15.4 & 61.3 & 14,8 \\
M. kobus var. borealis & 50 & 78 & 62 & 2 & 32 & 15 & 10 & 55.1 & 24,2 \\
M. obovata & 36 & 158 & 120 & 9 & 69 & 47 & 11.2 & 47.8 & 39.1 \\
M. officinalis & 166 & 240 & 210 & 6 & 65 & 31 & 8.4 & 25.3 & 14.7 \\
M. salicifolia & 40 & 55 & 60 & - & 1 & - & - & 1.7 & - \\
M. sieboldii & 26 & 52 & 48 & 6 & 39 & 28 & 13.4 & 64.2 & 58.2 \\
M. tripetala & 74 & 112 & 96 & 4 & 86 & 55 & 4.1 & 86.8 & 57.5 \\
\hline
\end{tabular}

$\mathrm{PSP}=$ potential seed productivity, $\mathrm{RSP}=$ real seed productivity, $\mathrm{PR}=$ productivity rate.

Characteristics of seeds and fruits of Magnolia taxa are presented in Table 5. Large fruit aggregates $(8.7-15.0 \mathrm{~cm})$ and seeds $(0.8-1.3 \mathrm{~cm})$ are typical in $M$. officinalis, $M$. obovata and $M$. tripetala, while small ones $(3.2 \mathrm{~cm}$ ) are observed in M. salicifolia (Fig. 1H-K).

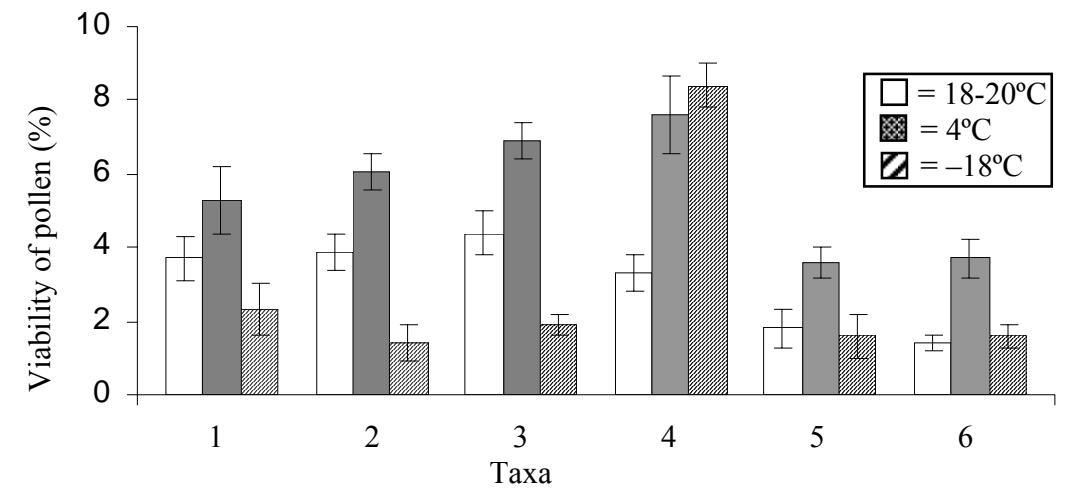

Fig. 2. Viability of Magnolia pollen after storage at different temperatures. 1. M. kobus, 2. M. kobus var. borealis, 3. M. obovata, 4. M. officinalis, 5. M. salicifolia, 6. M. sieboldii.

\section{Seed germination:}

Seed germination of Magnolia taxa in a cultivated condition in the south of Russian Far East showed that high germinating ability (67-94\%) is typical in M. tripetala, M. officinalis and M. obovata (Table 6). Despite a high productivity rate of $M$. kobus, germinating ability of its seeds is low, $3.0 \%$ to $4.4 \%$. Seed germination in the open ground and in the protected ground showed that optimal conditions for seeds of $M$. tripetala, M. officinalis and $M$. obovata are artificial stratification at $4^{\circ} \mathrm{C}$ during 30 days and further germination in the protected ground. Optimal conditions for $M$. sieboldii seeds are in the open ground (long-time stratification at $0^{\circ} \mathrm{C}$ to $-27^{\circ} \mathrm{C}$ ).

The present study revealed that a favourable effect on seed germinating ability was observed for $M$. obovata only $57.3 \%$ without sarcotesta and $94.3 \%$ with sarcotesta. No sarcotesta effects on seed germination were registered for other species. 
Table 5. Morphometric characteristics of the fruits and seeds of seven taxa of Magnolia.

\begin{tabular}{|c|c|c|c|c|c|c|c|}
\hline \multirow[b]{2}{*}{ Taxa } & \multicolumn{3}{|c|}{ Fruit } & \multicolumn{4}{|c|}{ Seed } \\
\hline & $\begin{array}{l}\text { Length } \\
(\mathrm{cm})\end{array}$ & $\begin{array}{l}\text { Width } \\
(\mathrm{cm})\end{array}$ & $\begin{array}{l}\text { Weight } \\
\text { (g) }\end{array}$ & Length $(\mathrm{cm})$ & Width $(\mathrm{cm})$ & $\begin{array}{c}\text { Weight (S) } \\
1000(\mathrm{~g})\end{array}$ & $\begin{array}{c}\text { Weight (WS) } \\
1000(\mathrm{~g})\end{array}$ \\
\hline M. kobus & $7.2 \pm 0.8$ & $2.1 \pm 0.06$ & $9.5 \pm 0.7$ & $0.9 \pm 0.01$ & $0.8 \pm 0.02$ & 323 & 169 \\
\hline $\begin{array}{l}\text { M. kobus var. } \\
\text { borealis }\end{array}$ & $4.5 \pm 0.1$ & $2 \pm 0.1$ & $8.9 \pm 0.9$ & $0.8 \pm 0.02$ & $0.7 \pm 0.02$ & 226.9 & 122 \\
\hline M. obovata & $8.7 \pm 0.3$ & $4.6 \pm 0.12$ & $43.3 \pm 3.3$ & $1.1 \pm 0.02$ & $0.9 \pm 0.01$ & 262.5 & 152.6 \\
\hline M. officinalis & $15 \pm 0.5$ & $4.9 \pm 0.07$ & $108.8 \pm 8.5$ & $1.3 \pm 0.01$ & $1.1 \pm 0.02$ & 528.2 & 399.3 \\
\hline M. salicifolia & $3.2 \pm 0.7$ & $1.2 \pm 0.6$ & $2.2 \pm 0.4$ & $0.8 \pm 0.01$ & $0.7 \pm 0.01$ & - & - \\
\hline M. sieboldii & $5.3 \pm 0.9$ & $2.07 \pm 0.02$ & $3.4 \pm 0.1$ & $0.5 \pm 0.02$ & $0.48 \pm 0$ & 52.7 & 39.5 \\
\hline M. tripetala & $7.2 \pm 0.2$ & $3.9 \pm 0.09$ & $40.3 \pm 2.2$ & $0.8 \pm 0.02$ & $0.7 \pm 0$ & 151.98 & 99.5 \\
\hline
\end{tabular}

$\mathrm{S}=$ seeds with sarkotesta, $\mathrm{WS}=$ seeds without sarkotesta, $-=$ not examined.

Table 6. Seed germination of seven taxa of Magnolia in different condition.

\begin{tabular}{|c|c|c|c|c|}
\hline \multirow[t]{2}{*}{ Taxa } & \multicolumn{2}{|c|}{$\%$ of seeds germination in greenhouse } & \multicolumn{2}{|c|}{$\begin{array}{l}\% \text { of seed germination in the open } \\
\text { ground }\end{array}$} \\
\hline & with sarcotesta & without sarcotesta & with sarcotesta & without sarcotesta \\
\hline M. kobus & 3 & 0 & $4.4 \pm 0.1$ & 0 \\
\hline M. kobus var. borealis & 0 & 0 & 0 & 0 \\
\hline M. obovata & $94.3 \pm 5.7$ & $57.3 \pm 4.7$ & $59.8 \pm 12.6$ & $45.5 \pm 7.8$ \\
\hline M. officinalis & $70.1 \pm 11,8$ & $47.3 \pm 1,3$ & $61 \pm 5.9$ & $45.5 \pm 6.1$ \\
\hline M. salicifolia & - & - & - & - \\
\hline M. sieboldii & $37.7 \pm 2.3$ & $56.7 \pm 5.7$ & $42.4 \pm 3.9$ & $52 \pm 6.1$ \\
\hline M. tripetala & $67.3 \pm 11.6$ & $56 \pm 5.8$ & $66.6 \pm 15.04$ & $47.8 \pm 9.4$ \\
\hline
\end{tabular}

' 0 ' denotes not germinated, '-' denotes not examined.

The present study addresses phenology of seven taxa of the genus Magnolia L., pollen biology of germination and storage conditions, seed productivity, germinating ability of seeds and its dependence on stratification and germination conditions. It was found that the flowering period of the taxa being studied occurs in May - June at a time of low air temperatures varying from $9^{\circ} \mathrm{C}$ to $14.5^{\circ} \mathrm{C}$, which has adverse effects on pollen viability. Due to this circumstance, $M$. kobus, $M$. obovata, M. officinalis, M. tripetala, M. salicifolia and M. sieboldii are characterized by low pollen fertility (9.4-31.7\%) in the south of the Russian Far East which affects their seed productivity. Real seed productivity of these taxa is considerably lower (1-55 seeds per one fruit aggregate) than their potential seed productivity (48-210 ovules per one fruit aggregate). Despite their low pollen viability and productivity rate, M. tripetala, M. officinalis and M. obovata in a cultivated condition produce seeds with high germinating ability (67-94\%). At the same time, $M$. sieboldii features a high productivity rate but low seed germinating ability. Seed germination results showed that optimal conditions for species with high germinating ability such as $M$. tripetala, M. officinalis and M. obovata are artificial stratification, presence of sarcotesta and protected ground conditions. We believe that low germinating ability of $M$. sieboldii and $M$. kobus in the protected ground can be explained by stratification duration and temperature. Sarcotesta effects on higher seed geminating ability were observed for $M$. obovata only. 


\section{References}

Barkalov, V.Y. 2009. Flora of the Kuril Islands. Dalnauka, Vladivostok. 54 pp.

Golubinsky, I.N. 1974. Biology of germination of pollen. Naukova Dumka, Kiev. 368 pp.

Grigorenko, I.V. 1998. Flowering ecology of the family Magnoliaceae Juss. in the industrial city of the South-east of Ukraine. Problems Dendrology, floriculture, horticulture. Abstracts of the VI Confer. Yalta. pp. 12-17.

Han, C.-Y. and Long, C.-L. 2010. Seed dormancy, germination and storage behavior of Magnolia wilsonii (Magnoliaceae), an endangered plant in China. Acta Bot. Yun. 32(1): 47-52.

Hirayama, K. and Ishida, K. 2005. Effect of pollen shortage and self-pollination on seed production of an endangered tree Magnolia stellata. Ann. Bot. 95(6): 1009-1015.

Ishida, K. 1996. Beetle pollination of Magnolia praecocissima var. borealis. Plant Species Biology 11: 199206.

Kikuzawa, K. and Mizui, N. 1990. Flowering and fruiting phenology Magnolia hypoleuca. Plant Species Biology 5: 255-261.

Koksheeva, I.M. 2004. On the methods of determining the viability of the pollen in the genus Rhododendron L. (Ericaceae). Bot. Journal 89(6): 147-150.

Korshuk, T.P. and Palagecha, R.M. 2007. Magnolia L. Kiev University. Ukraine. 207 pp.

Lapin, P.I. 1967. Seasonal rhythm of woody plants and its significance for the introduction. Bull. GBS. 65:13-18.

Law, Y.W. 1996. Magnoliaceae. Flora Reipublicae Popularis Sinicae 30(1): 151-194.

Liza, S.A., Rahman, M.O., Uddin, M.Z., Hassan, M.A. and Begum, M. 2010. Reproductive biology of three medicinal plants. Bangladesh J. Plant Taxon. 17(1): 69-78.

Minchenko, N.F. and Korshuk, T.P. 1987. Magnolias in Ukraine. Nauk. Dumka, Kiev. 184 pp.

Pshennikova, L.M. 2007. Lilac, cultivated in the Botanical Garden-Institute FEB RAS. Dalnauka, Vladivostok. $113 \mathrm{pp}$.

Rabotnov, T.A. 1960. Methods of study of seed reproduction of herbaceous plants in the communities. Geobotany field. Publishing House of the Academy of Sciences of the USSR, Moscow-Leningrad 2: 20-40.

Setsuko, S., Tamaki, I., Ishida, K., and Torami, N. 2008. Relationships between flowering phenology and female reproductive success in the Japanese tree species Magnolia stellata. Botany 86: 248-258.

Termena, B.K. 1972. About flowers and fruits of Magnolia soulangia in Bukovina. Bull. GBS. 84: 82-84.

Turkenya, V.G. 1991. Biological aspects of the monsoon climate zone of the Far East. Vladivostok: Far Eastern Branch of the Academy of Sciences of the USSR. 203 pp.

Wang, R. 2010. Flowering and pollination patterns of Magnolia denudata with emphasis on anatomical changes in ovule end seed development. Flora 205: 269-265.

(Manuscript received on 30 January 2013; revised on 9 October 2013) 